$\mathbb{T}$ periodica polytechnica

Mechanical Engineering

$51 / 1(2007) \sqrt{19} 22$

doi: 10.3311/pp.me.2007-1.03

web: http://www.pp.bme.hu/me

(c) Periodica Polytechnica 2007

RESEARCH ARTICLE

\section{New Linear-Electromagnetic Actuator Used for Cellular Phones}

\author{
Attila Halmai / Attila Lukács
}

Received 2007-03-18

\begin{abstract}
The mobile communication industry powered by electronics and information technology is building a transforming way for human communication. Electromechanical part, such as vibration motors, is essential components for mobile phones in order to come up with advance in the communication industry. The traditional vibrating component in mobile phones is a tiny rotating motor having an eccentric weight on top of the shaft. The size reduction, life span, reliability and productivity of mobile phones still remains the most prominent trend in the marketplace and demands a continual effort for the new construction. In this article, design of a linear-electromagnetic actuator is introduced.
\end{abstract}

\section{Keywords}

linear actuator - vibration motor $\cdot$ cellular phone - mechatronics

\section{Attila Halmai}

Department of Mechatronics, Optics and Instrumentation Technology, Faculty of Mechanical Engineering BME, H-1521 Budapest, Hungary

\section{Attila Lukács}

Department of Mechatronics, Optics and Instrumentation Technology, Faculty of Mechanical Engineering BME, H-1521 Budapest, Hungary e-mail: lukacs@mogi.bme.hu

\section{Introduction}

The mobile phone is an essential gadget in modern society life as a personal communication and multimedia function device. Thus, the mobile phone became one of the most important devices in the communication industry. As the multimedia function requires fast response, long life-time, high performance vibration motors for a silent paging signal, the optimal design using the dynamics characteristics simulation has been more an issue than ever before.

The actuators compose one component of mechatronics systems [1]. The electromagnetic actuators have a significant influence in the group of actuators which all contain micromotors. They can be grouped on the basis of force/torque generation in the following: Actuators, by Lorentz force or by electromagnetics interaction. Cellular phones use only an ironless, DC micromotor (Fig. 1) based on Lorentz force to cause a vibration function nowadays. Conventional vibration motors employ three-phase windings with a set of mechanical brushes [2].

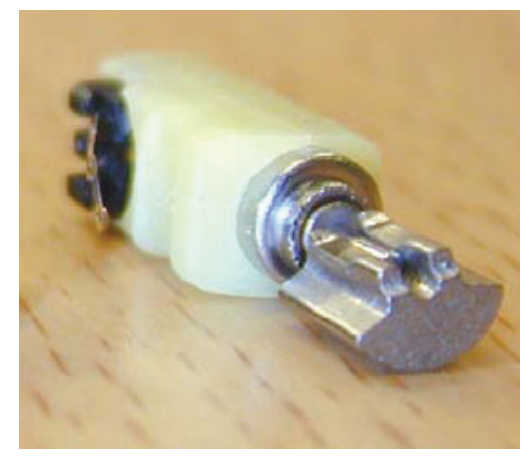

Fig. 1. A vibration motor composed of a DC motor and an eccentric mass called counterweight

It can be seen that the construction of the motors is changing [3. 4]. The main endeavour is to put end of the commutation with conventional brushes and commutators [5]. This task can be solved by a brushless DC electric motor but its price is not make competitive. The other way could be the modifying of the present construction. The linear actuator comes here to the front. In this paper there is introduced our new, linear-electromagnetic actuator (Fig. 2) and its measurement results. This prototype 
(Fig. 3) is manufactured by the authors who employ a shaker vibration algorithm. Nothing that the vibration mechanism is affected by electromagnetic field distribution in shaker algorithm, coupling analysis between mechanical and electromagnetic field is necessary.

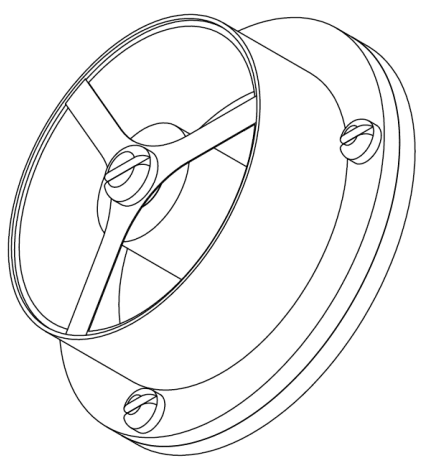

Fig. 2. Manufactured linear-electromagnetic actuator

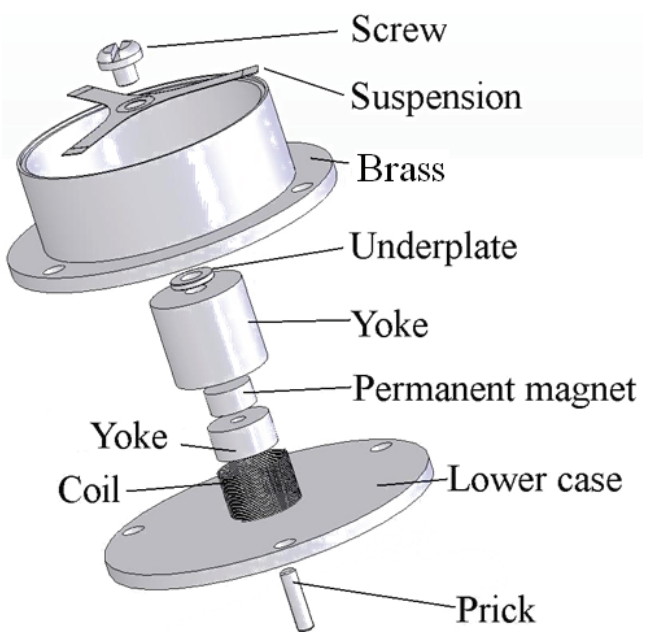

Fig. 3. Schematic drawing of the linear-electromagnetic actuator

\section{Linear-electromagnetic Actuator}

This part describes our linear-electromagnetic actuator which is used in cellular phones to cause a vibration function. Its usable frequency range is from 120 to about $180 \mathrm{~Hz}$ because human skin has the highest sensitivity to vibrating force in this frequency range [6]. The linear electromagnetic actuator derives its name from the method of force generation. The electromotive force - EMF which causes motion is produced electrodynamically by the interaction between a current flow in the coil and the magnetic field which passes through the coil, as illustrated in Fig. 4 .

The magnetic exciting force resulting from the interaction between the magnetic field and the total electric currents can be expressed as:

$$
F_{c}=\int I d l \times B
$$

The standing coil is located in the annular air-gap of the moving magnetic circuit. The magnetic circuit (yoke, permanent magnet) is made of soft iron. The mass of the magnetic circuit is called $m(\mathrm{~kg})$.
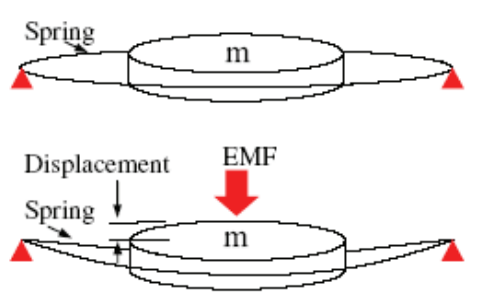

Fig. 4. Schematic diagram of generating the vibrating force of the massspring system in the linear electromagnetic actuator without EMF and under EMF

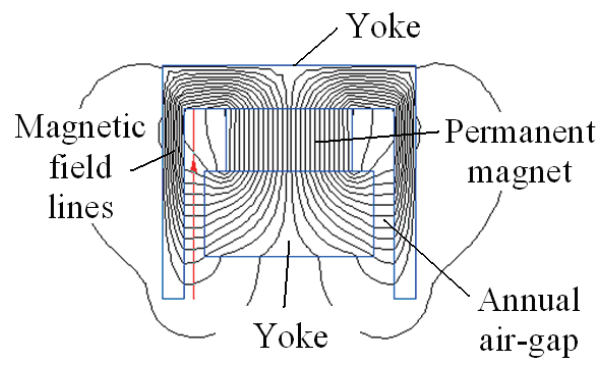

Fig. 5. Magnetic circuit of the linear electromagnetic actuator

The yoke is magnetically energized by an axial permanent magnet with two poles (Fig. 5), generating a radially directed field (Fig. 6) in the air gap, which is perpendicular to the direction of current flow in the armature coil. The generated force in the permanent magnet is in the direction of the axis of permanent magnet, perpendicular to the lower case. The direction of force is also perpendicular to the coil current direction and to the airgap field direction. Motion results when current passes through the coil. Motion of the magnetic circuit in all other directions is resisted by stiff restraints (prick).

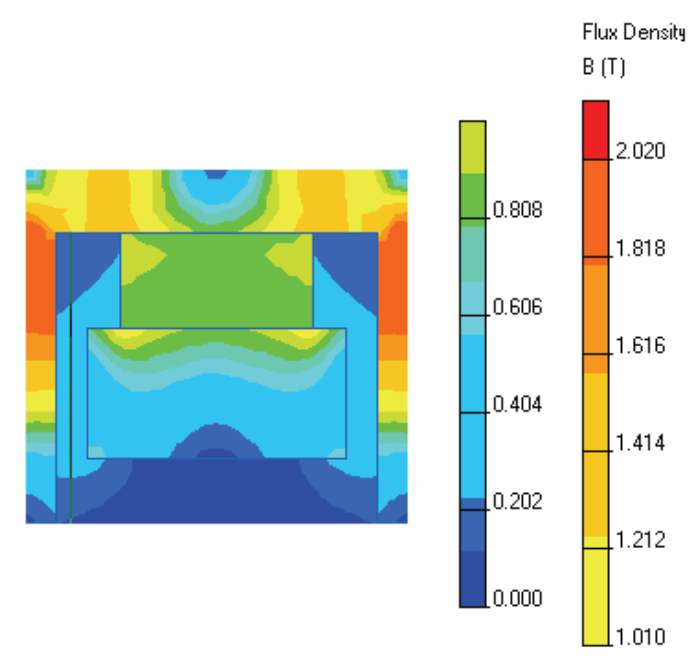

Fig. 6. Radially directed field in the air gap (finite element analysis)

The magnetic circuit assembly is supported by metal springs, permitting rectilinear motion, corresponding in direction to the axis of the coil current. Its advantages are a clean waveform, free vibration and rectilinear displacement with little damping $(k$ $[\mathrm{Ns} / \mathrm{m}] \rightarrow 0)$. The vibrator [7] can be described also one D.o.F. mass-spring system (Fig. 7) which is resonated by electromagnetic force at the fundamental natural frequency of system to 
generate and transmit the vibration signal to customers.

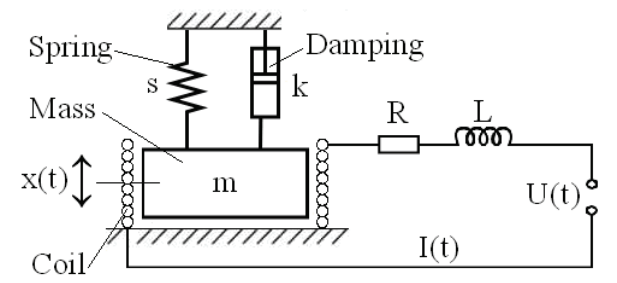

Fig. 7. Mechanical and electrical system analogy of the actuator

Coil current - I(t) can also be determined by solving the voltage equation of the equivalent circuit (Fig. 7) :

$$
L \dot{I}(t)+R I(t)+B l N \dot{x}(t)=U(t)=U_{0} \sin (\omega t)
$$

where $U(\mathrm{~V}), \omega(\mathrm{rad} / \mathrm{s}), R,(\Omega) I(\mathrm{~A}), N(-)$ and $L(\mathrm{H})$ denote applied voltage, exciting frequency, coil resistance, coil current, number of wires and inductance, respectively. The coil motion generates the back electromotive force, $B l N \dot{x}(t)$, manifesting coupling effects, where $l[\mathrm{~m}], x(t)[\mathrm{m}]$ and $\dot{x}(t)[\mathrm{m} / \mathrm{s}]$ are the coil length, moving magnetic circuit displacement and velocity.

In the simplest case of a spring - mass system is based on the assumption that the elastic spring obeys Hooke's law i.e. the characteristic curve of restoring force versus displacement is a straight line. However, many materials do not exhibit such a linear characteristic like in our case. The spring sometimes exhibits a characteristic such that the restoring force $\left(F_{S}\right)$ increases more rapidly than the displacement. Such characteristic is hardening (Fig. 8).

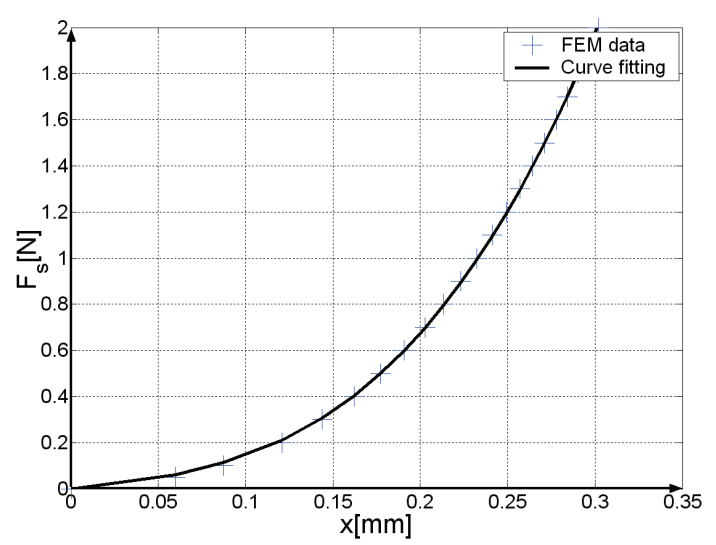

Fig. 8. Restoring force characteristic curves for hardening vibration system

The prototype has been manufactured using metal springs. The spring force $\left(F_{S}\right)$ - displacement $(x)$ characteristics of our linear electromagnetic actuator was investigated by a finite element analysis. As shown in Fig. 8 (“+”) the restoring force - displacement relationship was a nonlinear function. Our excited system with hardening restoring force may be described approximately by an equation of the form

$$
m \ddot{x}(t)+F_{s}=F_{e}=B l N I(t)
$$

where the $F_{s}(x)=s\left(x+\mu x^{3}\right)$ equation refers to the hardening characteristic. The $s(\mathrm{~N} / \mathrm{mm}), \mu\left(1 / \mathrm{mm}^{2}\right)$ are spring stiffness and non-linearity parameter. Curve fitting uses the nonlinear least squares formulation to fit a nonlinear model to FEM data. As noted, a regression equation takes the form $F_{s}(x)=s\left(x+\mu x^{3}\right)$. Our goal was to select the values of $s=0.798\left(\frac{\mathrm{N}}{\mathrm{mm}}\right)$ and $\mu=$ $80.6\left(\frac{1}{\mathrm{~mm}^{2}}\right)$ that will yield the curve minimizing $[8]$ :

$$
\sum_{k=1}^{m}\left(F_{i}-s\left(x_{i}+\mu x_{i}^{3}\right)\right)=\min .
$$

The fundamental natural frequency of the mass-spring system $\alpha$ is calculated as follows [9]:

$$
\begin{aligned}
\alpha=\sqrt{\frac{s}{m}}\left(1+\frac{3}{8} \mu a^{2}-\frac{21}{256} \mu^{2} a^{4}+\ldots\right) \cong \sqrt{\frac{s}{m}}=\sqrt{\frac{798(\mathrm{~N} / \mathrm{m})}{0.001(\mathrm{~kg})}}= \\
\quad 893\left(\frac{\mathrm{rad}}{\mathrm{s}}\right) \cong 142(\mathrm{~Hz})
\end{aligned}
$$

\section{Calibration and Applied Questions of the Transmis- sion Optogate - TIL 138}

Photoelectric transducers are typical measuring devices of displacement under millimeter. Their main advantage is that they do not put force in unknown object and they have a large cut-off frequency. A TIL 138 transmission optogate was used in the measurement. Circuit diagram of the photoelectric (voltage - displacement) transducer can be seen in Fig. 9

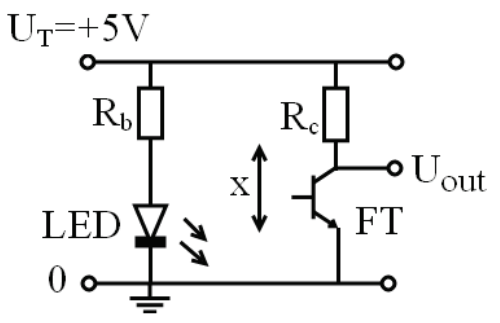

Fig. 9. Circuit diagram of the photoelectric (voltage - displacement) transducer

The additional resistant of the light source (LED) is $200[\Omega]$, the loading resistance of the detector - phototransistor is $4.7[\mathrm{k} \Omega]$. An optical non-transparent wedge is fixed on the top of the actuator by the way of cementation which is able to move among the optoelectric pair. A piece of beam of rays is defecated by this hidden flag. Ideally the non-defecated beam current falls on the detector. The hidden flag has a wedge-form in order to enlarge the linear range of the voltage - displacement characteristics. A straight line $U=m x+b$ is fitted on the linear range of the $U(x)$ function (Fig. 10, where the parameters are: $m=-3.55\left[\frac{\mathrm{V}}{\mathrm{mm}}\right]$ and $b=11.35[V]$.

\section{Stability Analysis}

Consider a hardening system whose response curve is shown in Fig. 8. Suppose that the exciting frequency starts at a low value and increases continuously at a slow rate. The amplitude of the vibration (Fig. 11) also increases but only up to a point. In particular, at the point of vertical tangency of the response curve, a slight increase in frequency requires that the system perform in an unusual manner. It "jump" down in amplitude to 


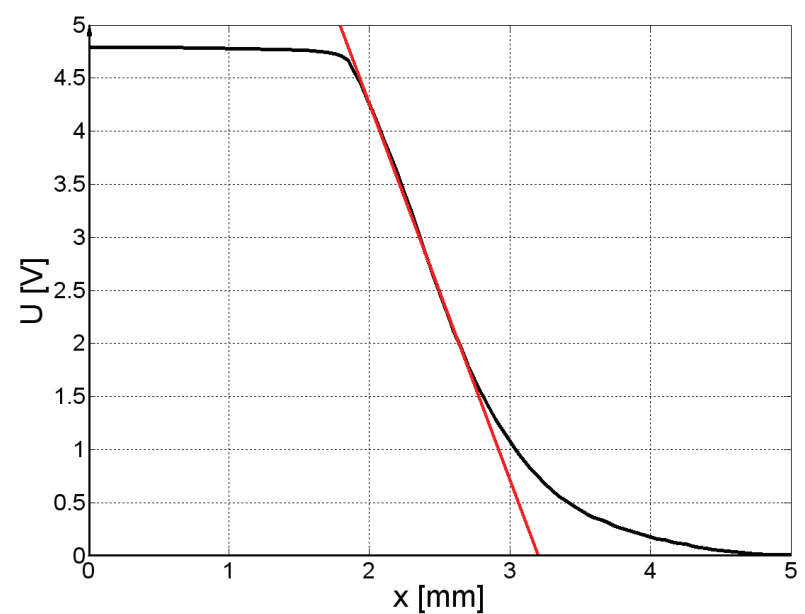

Fig. 10. Calibration curve of the transmission optogate - TIL 138

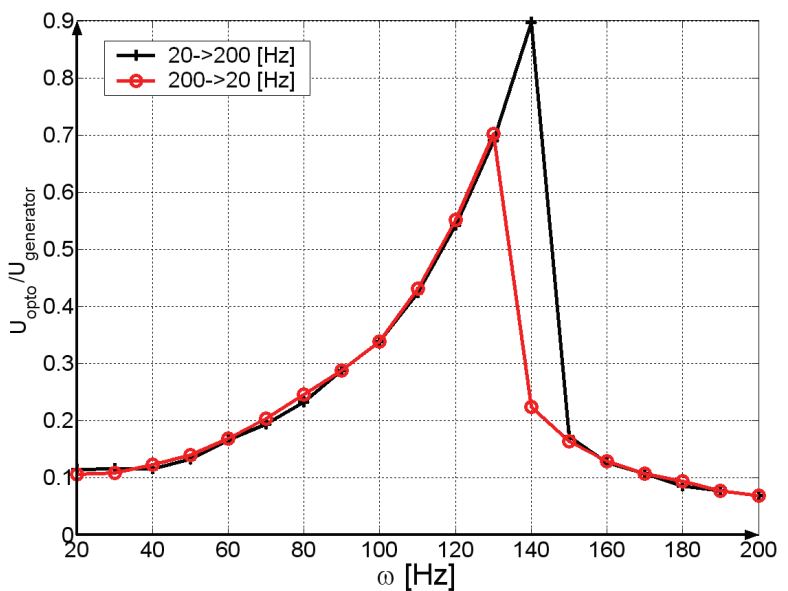

Fig. 11. Response curve for nonlinear system with hardening restoring force characteristic

the lower branch of the response curve. This experiment may be repeated by starting with a large value of exciting frequency, but requiring that the forcing frequency be continuously reduced. A similar situation again is encountered. The system must jump up in amplitude in order to meet the conditions of the experiment. The jump is not instantaneous in time, but requires a few cycles of vibration to establish a steady-state vibration at the new amplitude.

There is a portion of the response curve which is unattainable. It is not possible to obtain that particular amplitude by a suitable choice of forcing frequency. Thus, for certain values of $\omega$ there appear to be three possible amplitudes of vibration but only the upper and lower can actually exist. The direction of the jump depends on the direction of disturbance. Thus, of the three possible states of motion, one in phase and two out-ofphase with the exciting force, the one having larger amplitude of the two out-of-phase motions is unstable. This region in the response diagram is defined by the loci of vertical tangents to the response curve.

\section{Conclusions}

In this work, a new linear-electromagnetic actuator for cellular phones was designed and manufactured using metal springs. The fundamental natural frequency of the linearelectromagnetic actuator was $142[\mathrm{~Hz}]$ from $E q$. 5, which satisfy the required range (120-180[Hz]). However, further study needs to calculate the analytical solution of the equation of motion and giving a stability analysis.

\section{References}

1 Halmai A, Új konstrukciójú elektromágneses aktuátorok a mechatronikában: A tárcsás forgórészú egyenáramú motorok, Budapest, 1997. Habilitációs értekezés.

2 Chung S. U. - Hwang, A Design of a Two-phase Permanent Magnet Vibration Motor Used for Mobile Phones, Journal of Applied Physics 91 (2002 May), no. 10, 6985-6987.

3 Lee HJ, Chung SU, Development and Manufacturing of Hexahedral Type Vibration Motor Used for Mobile Phone, Journal of Materials Processing Technology 130-131 (2002), 685-690.

4 Lee HJ, Hwang SM, Design of an Integrated Microspeaker and Vibration Motor Used for Mobile Phones, Journal of Applied Physics 93 (May 2003), no. 10, 8516-8518.

5 Chung SU, Hwang GY, Development of Brushless and Sensorless Vibration Motor Used for Mobile Phone, IEEE Transactions on Magnetics 38 (September 2002), no. 5 .

6 Kaaresoja T, Linjama J, Perception of Short Tactile Pulses Generated by a Vibration Motor in a Mobile Phone, IEEE Proceedings of the First Joint Eurohaptics Conference and Symposium on Haptic Interfaces for Virtual Environment and Teleoperator Systems (2005).

7 Kim T J, Hwang S M, Analysis of Vibration for Permanent Magnet Motors Considering Mechanical and Magnetic Coupling Effects, EEE Transactions on Magnetics 36 (July 2000), no. 4.

8 Lagarias JC, Reeds JA, Wright $\mathbf{M H}$, Wright PE, Convergence Properties of the Nelder-Mead Simplex Method in Low Dimensions, SIAM Journal of Optimization 9 (1998), no. 1, 112-147.

9 Ludvig Gy, Gépek dinamikája, Múszaki Könyvkiadó, Budapest, 1973. 